\title{
Metabarcoding Gillnets to Assess Unaccounted Catch Depredation or Escape
}

\author{
Mark de Bruyn ( $\square$ mark.debruyn@sydney.edu.au ) \\ University of Sydney https://orcid.org/0000-0003-1528-9604 \\ Matteo Barbato \\ University of Sydney https://orcid.org/0000-0001-5368-2090 \\ Matt Broadhurst \\ Southern Cross University
}

\section{Article}

Keywords: metabarcoding, illegal, unreported and unregulated (IUU) fishing, trace DNA, fisheries, forensics

Posted Date: December 3rd, 2020

DOl: https://doi.org/10.21203/rs.3.rs-112279/v1

License: (1) This work is licensed under a Creative Commons Attribution 4.0 International License.

Read Full License

Version of Record: A version of this preprint was published at Environmental DNA on June 30th, 2021.

See the published version at https://doi.org/10.1002/edn3.234. 
1 Metabarcoding gillnets to assess unaccounted catch depredation or escape

2

3 Running title: Sequencing shark nets

4

5 Mark de Bruyn ${ }^{1 *}$, Matteo Barbato ${ }^{1,2}$, and Matt K. Broadhurst ${ }^{3,4 *}$.

6

7 Affiliations:

$8{ }^{1}$ The University of Sydney, School of Life and Environmental Sciences, Sydney, NSW 2006,

$9 \quad$ Australia.

10

${ }^{2}$ Department of Biology, University of Padova, Padova, Italy.

12

${ }^{3}$ NSW Department of Primary Industries, Fisheries Conservation Technology Unit, National

14 Marine Science Centre, Southern Cross University, 2 Bay Drive, Coffs Harbour, NSW 2450, 15 Australia.

16

$17{ }^{4}$ Marine and Estuarine Ecology Unit, School of Biological Sciences, University of

18 Queensland, St Lucia, Australia.

19

$20 *$ Correspondence to: mark.debruyn@sydney.edu.au \& matt.broadhurst@dpi.nsw.gov.au 


\section{Abstract}

22 Gillnets are the world's most common net-based fishing gear, comprising walls of light mesh designed to entangle fish. Like all fishing gears, gillnets are not $100 \%$ effective for the

24 targeted catches, and usually catch similar-sized, unwanted animals that are discarded, often 25 dead. Gillnets are often retrieved with holes in the netting, which means some animals escape 26 or are depredated unseen, but with some mortality. To effectively manage fisheries around 27 the world, information is required on not only the harvested and discarded mortalities, but also problematic interactions and mortalities caused by the fishing gear and especially those involving protected species. This study sought to assess a novel method for determining such interactions by sampling pieces of netting around holes in polyethylene gillnets for environmental deoxyribonucleic acid or 'eDNA'. Here we show that eDNA correctly identified all previously entangled-and-landed species. Also, eDNA from three uncaptured taxa were recorded: bull shark, Carcharhinus leucas, white shark, Carcharodon carcharias and dolphins (Delphindae), illustrating the potential to reveal previously cryptic gillnet interactions. We propose that as scientific methods evolve and autonomous real-time DNA surveillance becomes routine, eDNA testing of fishing gears and vessels could provide a novel, complementary fishery-monitoring tool.

\section{Keywords}

40 metabarcoding; illegal, unreported and unregulated (IUU) fishing; trace DNA; fisheries; 41 forensics 


\section{Introduction}

No fishing gear is entirely selective for the targeted catches, which means that in addition to a global harvest from marine fisheries of $\sim 80$ million $\mathrm{t}$ p.a., an additional $\sim 10$ million $\mathrm{t}$ of nontarget organisms (termed bycatch) is discarded, mostly dead(Zeller, Cashion, Palomares, \& Pauly, 2018). These collateral mortalities have raised concerns over deleterious cascading effects on ecosystems, especially among priority stocks which include endangered, threatened and protected (ETP) species (Gray, \& Kennelly, 2018; Zeller, Cashion, Palomares, \& Pauly, 2018; Hall, 1996). Recognition of these issues has supported ongoing global bycatch resolution efforts, typically via technical modifications to fishing gears, but also spatial and temporal fishing closures (reviewed by Hamilton, \& Baker, 2019; Uhlmann, \& Broadhurst, 2015; Gilman et al., 2006; Broadhurst, 2000).

Beyond bycatch mortality are other important, less-studied impacts of fishing gears involving cryptic injuries or deaths of organisms after escaping or being depredated (Uhlmann, \& Broadhurst, 2015; Warden, \& Murray, 2011; Broadhurst, Suuronen, Hulme, 2006). The extent of collateral impacts is likely gear-specific, but some fishing methods, and especially gillnetting, probably evoke extensive cryptic mortalities (Gray, \& Kennelly, 2018). In many cases, animals are meshed and then either depredated or drop out of gillnets, without being recorded (Uhlmann, \& Broadhurst, 2015). Cryptic encounters need to be quantified to comprehend fishing-gear impacts and to identify priorities for conservation efforts, particularly for ETP species (Warden, \& Murray, 2011).

Surveillance systems are ever evolving to provide new options for monitoring fishing gears, and traditionally include hydroacoustics (Flowers, \& Hightower, 2013) and camera systems (Underwood, Winger, \& Legge, 2012), which have expanded to encompass drones 
67 (Toonen, \& Bush, 2020). Another possible option for assessing broader impacts of a fishing gear is residual deoxyribonucleic acid (DNA) metabarcoding. Recently, there have been considerable advancements in using DNA to determine species identification, genetic diversity, dispersal, inbreeding, and relative population abundances-even from trace levels of material via metabarcoding (Yates, Fraser, \& Derry, 2019; Bakker et al., 2017; Stat et al., 2017). The sensitivity of new approaches has burgeoned into the research field of 'environmental DNA' (eDNA) to evaluate patterns and processes in biodiversity science (Deiner et al., 2017; Barnes, \& Turner, 2016; Bohmann et al., 2014).

\section{Conceivably, during capture organisms embed tissue within mesh twine structures, and} DNA metabarcoding could be used to identify these taxa. Here we propose a new application of DNA metabarcoding to sections of netting from gillnets targeting sharks (mostly carcharhinids) as part of a trial to improve bather protection off New South Wales (NSW), Australia. We compared these data against recorded species entanglements, including those listed as ETP (Broadhurst, \& Cullis, 2020). We sought to test whether those species that remained trapped, or escaped or were depredated from the gillnets, left traces of their DNA in the netting strands.

\section{Materials and Methods}

\section{Fishing gear and sampling}

The methods were performed in accordance with relevant guidelines and regulations and approved by NSW Department of Primary Industries. Samples were collected from two identical bather-protection gillnets that were singularly and alternately deployed (along with various other replicate gillnets) in 5-8 $\mathrm{m}$ of water $\sim 500 \mathrm{~m}$ off Evans Head, NSW $\left(29.11^{\circ} \mathrm{S}\right.$, 153.44 ${ }^{\circ}$ E) between 30 December, 2016 and 21 March, 2017 (Fig. 1; Broadhurst, \& Cullis, 
92 2020, for specific technical details). Attempts were made to always continuously fish one

93 gillnet, and to check and clear it every 12 to $24 \mathrm{~h}$ and replace as required. All gillnet

94 checks/replacements were done with an onboard scientific observer. During each check, any entangled animals were removed, identified, sexed and measured. Any damage to gillnets was recorded and contact and escape/depredation were considered to have occurred when there was no animal entangled, but there were two or more broken adjacent bars (Fig. 1; creating a hole at least $600 \times 600 \mathrm{~mm})$.

\section{Sampling of the gillnet twines (1.8-mm diameter braided polyethylene) was done} opportunistically. In each case, gillnets were sampled for twines before their deployment ('pre-fishing') and after being stored in air for 27-323 days and then again ('fishing') during a check when there was damage as defined above (Figs 2 and 3). On one occasion, twine samples were taken around an entangled blacktip shark, Carcharhinus limbatus $(224 \mathrm{~cm}$ total length; TL) as a positive control. During twine sampling, a researcher wearing sterile gloves cut (using sterilised scissors) five replicate pieces ( $\sim 2 \mathrm{~cm}$ in length) from randomly selected locations of the bagged and dry-stored gillnet, or around the perimeters of large holes or the captured blacktip shark, and placed these into sealed vials containing ethanol.

\section{DNA extraction and amplification}

For each sample, the five replicate twine pieces were independently extracted using a Qiagen DNeasy Blood and Tissue kit following manufacturer's instructions. Ethanol precipitation was used to isolate DNA from the twine-storage ethanol prior to extraction (Barbato et al., 2019), while the twine was also targeted for DNA extraction by adding lysis buffer and Proteinase-K. Within samples, the extracts from each of the five replicates were then combined to maximise DNA yield. The DNA extraction was carried out in a pre-PCR 
laboratory to minimise contamination, and clean-room protocols were followed with extensive bleaching and UV treatment of the area and equipment. Filter pipette tips were used, and gloves frequently changed. Negative controls were included for all stages of the work.

\section{Metabarcoding assay}

Two group-specific minibarcode primers were selected for teleosts and elasmobranchs, targeting 12S mitochondrial DNA (MiFish (Miya et al., 2015) and Elasmo02 (Taberlet, Bonin, Zinger, \& Coissac, 2018)). Polymerase chain reaction (PCR) was performed using the AmpliTaq Gold 360 protocol and thermocycling conditions recommended in (Taberlet, Bonin, Zinger, \& Coissac, 2018). The PCR hybridization temperatures were 50 and $59^{\circ} \mathrm{C}$ for MiFish and Elasmo02 primers, respectively, and products were run on a $1 \%$ agarose gel to confirm amplification of the correct target size. A second round of PCR was undertaken on the cleaned PCR products using unique dual-indexed primers on each sample, that included the Illumina adaptors. PCR products were sent to the Ramaciotti Centre for Genomics at the University of NSW for cleaning, normalising, and pooling before paired-end sequencing was performed on an Illumina MiSeq platform. Demultiplexing was conducted by the sequencing centre.

\section{Bioinformatic pipeline}

Demultiplexed Illumina reads were first processed using Geneious software for pairing, merging and trimming the forward/reverse primers (Kearse et al., 2012). Reads were discarded in the absence of a matching primer sequence and length, or an excessive number of nucleotide mismatches using Geneious's default settings. USEARCH was used to conduct the operational taxonomic unit (OTU) analysis (Edgar, 2010). Following USEARCH 
guidelines for OTU creation, reads were additionally quality filtered according to ambiguities $(\mathrm{N}=0$ ), length (minimum length $150 \mathrm{bp}$ ) and maximum error rate (error $<0.5)$.

Reads were then dereplicated into unique sequences and finally the UPARSE algorithm cluster_otus (97\% similarity) was applied to define OTUs. This algorithm facilitated removing possible sequencing errors, PCR artefacts, chimeras and low-abundance clusters $<0.75 \%$ from the total number of unique sequences identified within the sample. The USEARCH command otutab enabled mapping the relative abundance of each OTU within the sample of filtered reads. Read counts were assumed to approximate the biomass of tissue left embedded in the twine, and so those taxa with $<1 \%$ of total filtered reads per sample were deemed unlikely to be responsible for damage to gillnets.

The basic local alignment search tool (BLASTn) at the National Center for Biotechnology Information's (NCBI) GenBank nucleotide database (Altschul, Gish, Miller, Myers, \& Lipman, 1990) was executed for each samples' OTUs to assess taxonomic diversity. The BLASTn outputs were visualized using MEGAN6 (MEtaGenome ANalyzer) (Huson et al., 2016) to inspect taxonomic identification using the LCA parameter set as a minimum bit score of 150.0 and the top $5 \%$ of matches. Taxa other than marine megafauna were excluded from downstream analyses, but are listed in Supplementary Table 1. These species comprised standard metabarcoding contaminants (e.g. human, cows, pigs, and chickens), but also marine taxa including crustaceans and teleosts (mostly Clupeocephala), which probably interacted with the gillnets during fishing and/or were present on the predators caught in the gillnets.

\section{Results}


In total, gillnets one and two were cumulatively fished for 2403 and $1501 \mathrm{~h}$ catching 65 and

26 animals, comprising ten species and incurring 22 and 14 holes (4-1000 broken bars), respectively (Figs 1-3). The gillnets were temporally sampled for twines six and four times each, which encompassed 'pre-fishing' samples after 27, 34, 192 and 323 days storage in air, and then 'fishing' samples of holes (including the positive control) following deployment (but with repeated checking) after 4, 6 or 10 days (Figs 2 and 3).

172

A total of 2,104,024 raw reads were produced for the Elasmo02 dataset, and 1,275,623 for MiFish. After filtering, 2,016,447 Elasmo02 reads and 1,164,033 MiFish reads were retained for analyses. Negative controls showed extremely low levels of possible cross-contamination for the MiFish amplicons (Gnathostomata), but some cross-contaminating taxa were evident for Elasmo02 (Mobula spp., Aetobatus spp., sandy sprat, Hyperlophus vittatus, and analyses of the Elasmo02 dataset (Table 1).

The Elasmo02 amplicons correctly identified all elasmobranchs previously caught in the gillnets to genus, with relatively high numbers of reads in all cases (Table 1). The MiFish amplicons were no less accurate in identifying taxa, but recovered only a subset of the taxa identified in the Elasmo02 amplicons (Table 1). The MiFish dataset was dominated by human and teleost (Clupheocephala) reads, accounting for around $90 \%$ of the reads per sample

\section{(Supplementary Table 1).} 7

In most cases for sharks, assignments were only possible to Carcharhinus spp. or Sphyrna spp., but species level assignments were achieved for grey nurse shark, Carcharias taurus 190 (pre-fishing sample 3, and a species identified as previously being caught in the gillnet), and 

onboard the vessel used during sampling or in the laboratories; Table 1). Another identified group that was not previously caught in these gillnets or at the fishing location was Delphinidae (fishing sample 10, in both amplicon datasets), albeit at low reads $(<1 \%)$ for Elasmo02 (Table 1, Supplementary Table 1).

\section{Discussion}

This study demonstrates the utility of eDNA for detecting species interactions with PE twine used in gillnets. By sampling netting before deployment (after protracted storage) and from holes during fishing, we have not only resolved several cryptic mesopredator interactions, but also demonstrated the longevity of elasmobranch DNA in stored netting. This information, along with consideration of contamination issues, can be used to postulate the future potential and current limitations of eDNA as a novel surveillance system for monitoring fishing gears.

All pre-fishing samples comprised the DNA of species previously identified as catches in the gillnets, and with percentage reads that were somewhat proportional to earlier abundances (Broadhurst, \& Cullis, 2020). Specifically, both Sphyrna spp. and Rhinoptera spp. contributed large reads, which probably reflected recorded entanglements of great hammerheads, Sphyrna mokkaran and especially Australian cownose rays, Rhinoptera neglecta. While not as numerically abundant as $R$. neglecta, all $S$. mokkaran were very large (mean size of $\sim 3 \mathrm{~m} \mathrm{TL}$ ) and frequently tangled very large sections of netting (Broadhurst, \& Cullis, 2020). Conceivably, these animals would shed DNA across considerable areas, which might be expected to remain in twines, especially when gillnets were packed into bags and stored soon after specimens were caught. The presence of these species' DNA after $>320$ 
days is well within the timeframe from human forensics, whereby DNA can apparently remain viable on polypropylene twine for periods up to 23 years (theguardian.com/uknews/2019/oct/04/dna-discovery-raises-hopes-of-finally-finding-killer-of-melanie-hall (Steven Morris, 2019)).

In support of a supposition that the abundance of reads reflected the historical amount of gillnet interactions there was a high number of relevant reads in both Elasmo02 and MiFish for the positive control (sample 2; C. limbatus). However, this information does not distinguish temporal abundances. For example, in sample 2, the relatively high number of Rhinoptera spp. reads might have reflected six $R$. neglecta caught in the previous four days, or 23 individuals caught over the previous 11 months. Haplotype analysis of metabarcoding reads could be informative in future for determining the minimum number of individuals interacting with a gillnet, and to avoid repeat recording of the same interaction (Adams et al., 2019).

While pygmy devilrays, Mobula eregoodoo and whitespotted eagle rays, Aetobatus ocellatus were also caught in one or both gillnets respectively, and manifested as high DNA reads, negative controls revealed these taxa as sources of contamination in the Elasmo02 dataset. We advocate using a minimum of two primer sets to circumvent this problem. The MiFish dataset showed no such contamination issues, and identified Mobula and Aetobatus spp. only in those samples following capture. The contamination source remains unknown, but possibly reflects earlier research on M. eregoodoo diet (Barbato et al., 2019). This outcome underscores the requirement for negative controls throughout the sampling and labwork processes, and inclusion of multiple gene-target regions. 
242 from teleosts and crustaceans not recorded as caught (or observed) in the gillnets, but conceivably possible for the study area (Broadhurst, \& Cullis, 2020). These species might have contacted the vessel, but more likely meshes (e.g. teleosts were herded in by predators that were then entangled), or alternatively been present in the mouths of sharks and deposited on netting during escape. A similar hypothesis might support the observation of the Delphinidae DNA in gillnet two alongside that of C. carcharias. Neither animal was previously caught in the sampled gillnets or at the fishing site, nor handled onboard the gillnet-sampling vessel or by the crew. Potentially, the $C$. carcharias had already consumed a dolphin, or chased one into the gillnet and was then entangled, leaving a mixture of predator/prey DNA in the hole. Alternatively, the C. carcharias depredated an entangled dolphin. Broadhurst and Cullis (2020) recorded only 7\% of trapped animals as being depredated, but these might represent unsuccessful removals, considering the numbers of holes in the gillnets ( 36 holes vs 91 animals here). The same interactions might explain the high number of sequencing reads for the Rhinoptera spp. and C. leucas (which was also unique to the eDNA sample).

The data show DNA appears to remain viable for a considerable amount of time on stored polyethylene gillnets, and could potentially be useful as a long-term 'archive' of collective interactions with ETP species had occurred. Over time, such data could be used to infer problematic spatio-temporal fishing effort, and ultimately used to manage negative impacts. contamination; both on board fishing vessels, and post-sample collection. Further, the 
longevity of DNA on other materials commonly used in gillnets, and especially monofilament polyamide, remains unknown. These issues require careful consideration and assessment.

Environmental DNA is a rapidly evolving research area, with many possible applications for providing accurate spatio-temporal information on fishery interactions. On-board DNA processing devices, such as Oxford Nanopore Technologies' microfluidic device, the MinION, would provide capacity for near real-time monitoring. Decreasing costs of DNA analyses and sequencing will facilitate greater sampling effort, while increasing automation associated with these devices reduces the need for skills in molecular biology. Other technical developments required for broadscale uptake of DNA analyses into fisheries science include completed reference databases (e.g. GenBank), and further understanding of whether we can assess biomass and/or temporal effects from DNA data (e.g. do number of sequencing reads reflect many individuals, or more recent interactions). Notwithstanding such caveats, based on our results here, we propose eDNA will facilitate the future surveillance of problematic fishing gears.

\section{Acknowledgements}

284 This study was funded by the NSW Department of Primary Industries and the University of 285 Sydney. Thanks are extended to the crew of the FV 'Pluka' and Sean Blake, Isabelle 286 Thiebaud and Dylon Grogan for helping to collect the data. 


\section{References}

Adams, C. I. M. et al. Beyond biodiversity: can environmental DNA (eDNA) cut it as a population genetics tool? Genes 10(3), 192 (2019).

Altschul, S. F., Gish, W., Miller, W., Myers, E. W., \& Lipman, D. J. Basic local alignment search tool. Jnl. Mol. Biol. 215, 403-410 (1990).

Bakker, J. et al. Environmental DNA reveals tropical shark diversity in contrasting levels of anthropogenic impact. Sci. Reports, 7(1), 16886 (2017).

Barbato, M. et al. Metabarcoding for stomach-content analyses of pygmy devil ray (Mobula kuhlii cf. eregoodootenkee): comparing tissue and ethanol preservativederived DNA. Ecol. Evol. 9(5), 2678-2687 (2019).

Barnes, M. A., \& Turner, C. R. The ecology of environmental DNA and implications for conservation genetics. Cons. Genetics, 17(1), 1-17 (2016).

Bohmann, K. et al. Environmental DNA for wildlife biology and biodiversity monitoring. Trends Ecol. Evol. 29(6), 358-367 (2014).

Broadhurst, M. K. Modifications to reduce by-catch in prawn trawls: A review and framework for development. Rev. Fish Biol. Fish. 10, 27-60 (2000).

Broadhurst, M. K., Suuronen, P., \& Hulme, A. Estimating collateral mortality from towed fishing gear. Fish Fish. 7, 180-218 (2006).

Broadhurst, M.K. \& Cullis, B.R. Mitigating the discard mortality of non-target, threatened elasmobranchs in bather-protection gillnets. Fish. Res. 222, 105435 (2020).

Deiner, K. et al. Environmental DNA metabarcoding: Transforming how we survey animal and plant communities. Mol. Ecol. 26(21), 5872-5895 (2017).

Edgar, R. C. Search and clustering orders of magnitude faster than BLAST. Bioinformatics, 26, 2460-2461 (2010).

Flowers, H.J., \& Hightower, J.E. A novel approach to surveying sturgeon using side-scan sonar and occupancy modelling. Mar. Coastal Fish.: Dynamics, Management, and Ecosystem Sci. 5, 211-223 (2013).

Gilman, E. et al. Reducing sea turtle by-catch in pelagic longline fisheries. Fish \& Fish. 7(1), 2-23 (2006).

Gray, C. A., \& Kennelly, S. J. Bycatches of endangered, threatened and protected species in marine fisheries. Rev. Fish Biol. Fisheries 28, 521-541 (2018).

Hall, M. A. On bycatches. Rev. Fish Biol. Fisheries 6, 319-352 (1996).

Hamilton, S., \& Baker, G.B. Technical mitigation to reduce marine mammal bycatch and entanglement in commercial fishing gear: lessons learnt and future directions. Rev. Fish Biol. Fisheries 29, 223-247 (2019).

Huson, D. H. et al. MEGAN community edition - interactive exploration and analysis of large-scale microbiome sequencing data. PLoS Comp. Biol. 12(6), e1004957 (2016).

Kearse, M. et al. Geneious Basic: an integrated and extendable desktop software platform for the organization and analysis of sequence data. Bioinformatics, 28(12), 1647-1649 (2012).

Miya, M. et al. MiFish, a set of universal PCR primers for metabarcoding environmental DNA from fishes: detection of more than 230 subtropical marine species. Roy. Soc. Open Sci. 2(7), 150088 (2015).

Stat, M. et al. Ecosystem biomonitoring with eDNA: metabarcoding across the tree of life in a tropical marine environment. Sci. Reports, 7(1), 1-11 (2017).

Taberlet, P., Bonin A., Zinger L., Coissac E. Environmental DNA for Biodiversity Research and Monitoring. Oxford, UK. Oxford University Press (2018).

Toonen, H. M., \& Bush, S. R. The digital frontiers of fisheries governance: fish attraction devices, drones and satellites. Jnl. Env. Policy \& Plan. 22, 1-13 (2020). 
Uhlmann, S. S., \& Broadhurst, M. K. Mitigating unaccounted fishing mortality from gillnets and traps. Fish \& Fisheries, 16(2), 183-229 (2015).

Underwood, M., Winger, P. D., \& Legge, G. Development and evaluation of a new high definition self-contained underwater camera system to observe fish and fishing gear in situ. Jnl. Ocean Tech. 7(1), 59-70 (2012).

Warden, M. L., \& Murray, K. T. Reframing protected species interactions with commercial fishing gear: Moving toward estimating the unobservable. Fish. Res. 110(3), 387-390 (2011).

Yates, M. C., Fraser, D. J., \& Derry, A. M. (2019). Meta-analysis supports further refinement of eDNA for monitoring aquatic species-specific abundance in nature. Enviro. DNA 1(1), 5-13 (2019).

Zeller, D., Cashion, T., Palomares, M. \& Pauly, D. Global marine fisheries discards: a synthesis of reconstructed data. Fish Fish. 19(1). 30-39 (2018).

Author Contributions: MKB conceived the study. MB and MKB collected the data. MdB and $\mathrm{MB}$ conducted molecular lab work. MB analysed the data. MdB, MB and MKB wrote the paper.

Data Accessibility: The datasets generated and analysed during the current study will be archived in Genbank and/or Dryad. 


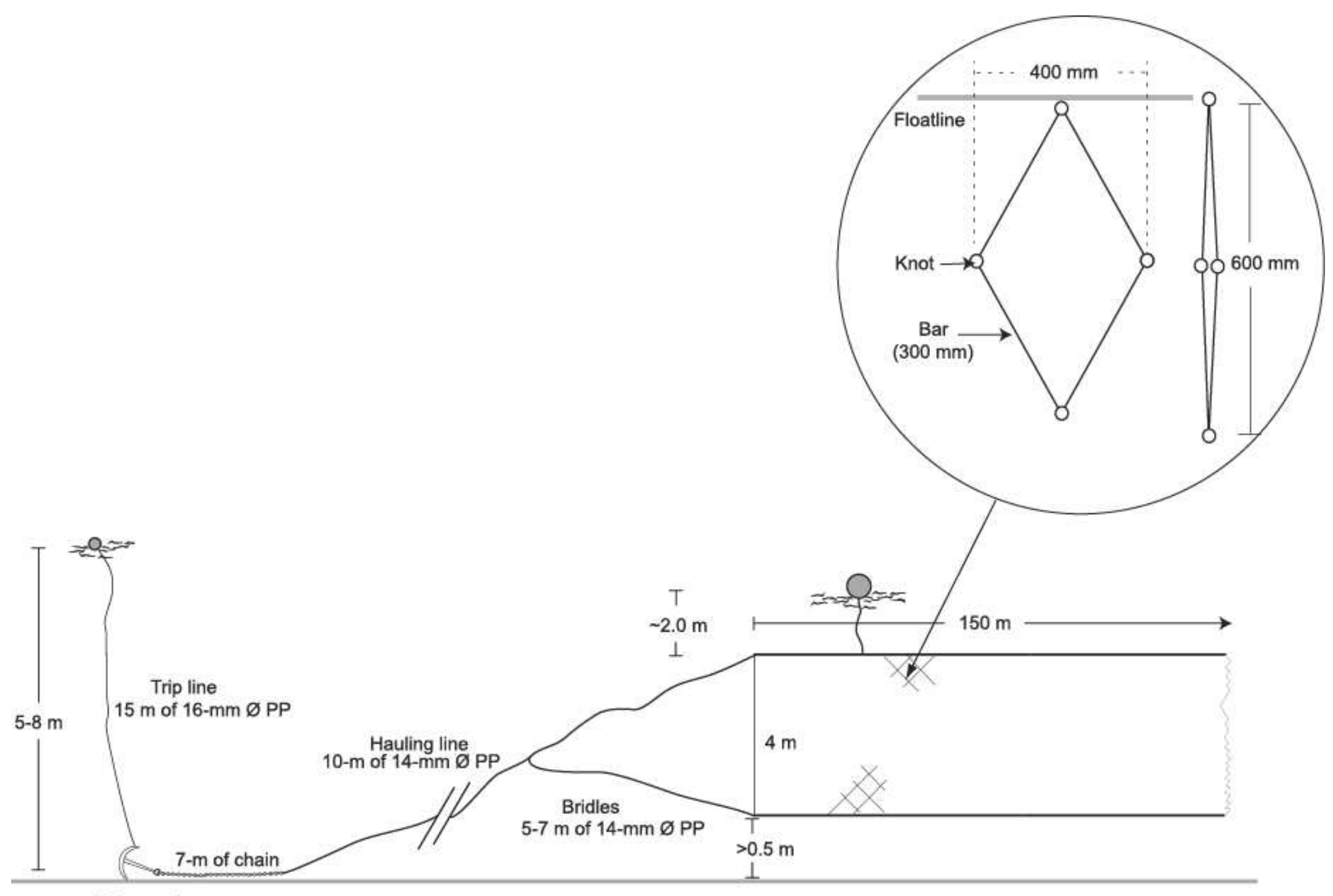

30-kg anchor

Fig. 1. Schematic diagram of the bather-protection gillnets fished off Evans Head (29.11 $\left.{ }^{\circ} \mathrm{S}, 153.44^{\circ} \mathrm{E}\right)$, Australia. 


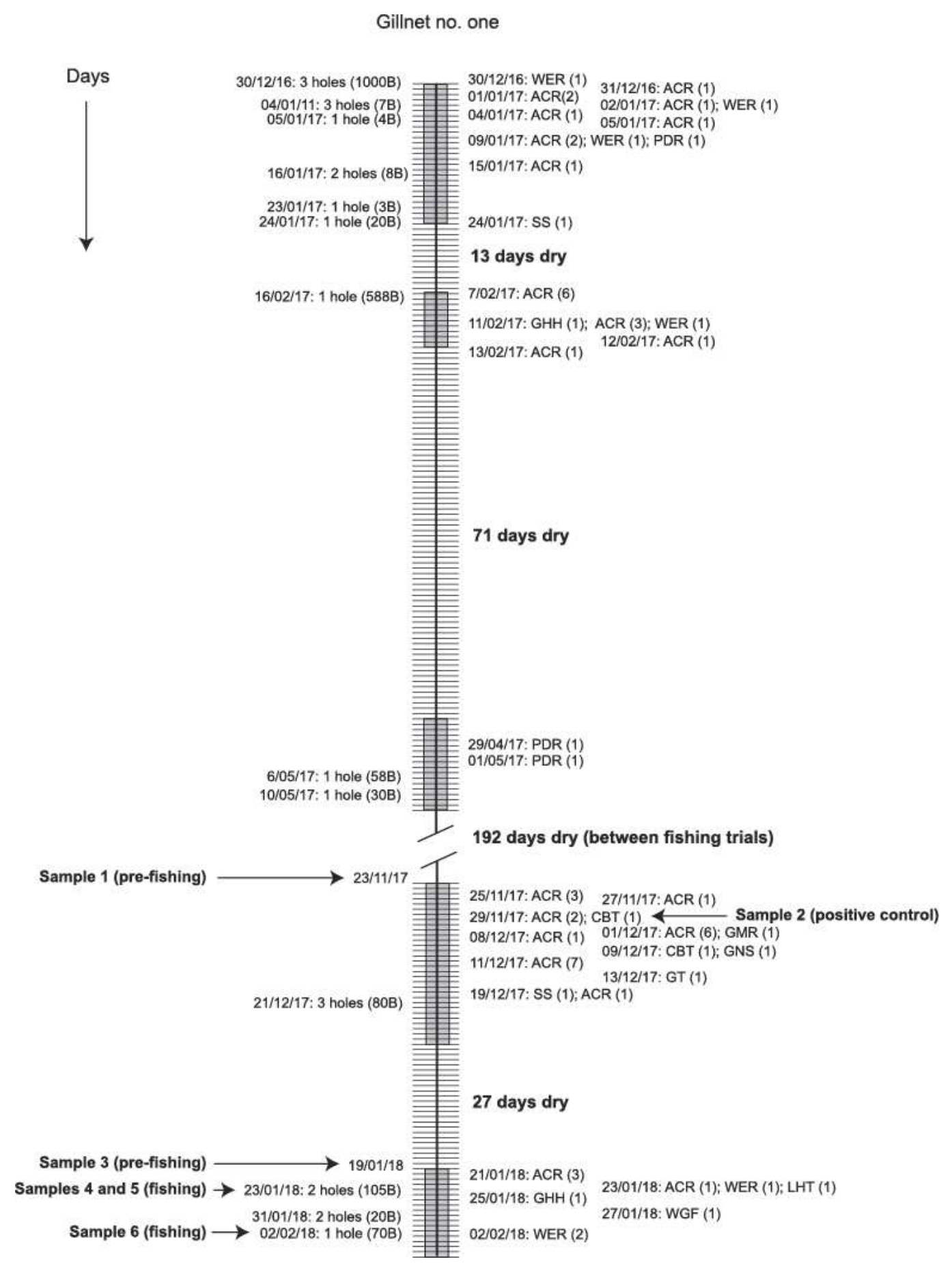

Fig. 2. Chronology of fishing (damage as holes and broken bars; $B$ and catches; $n=$ number) and sampling (eDNA collected) for gillnet no. 1 fished off Evans Head $\left(29.11^{\circ} \mathrm{S}, 153.44^{\circ} \mathrm{E}\right)$, Australia, with horizontal bars representing days in each of two fishing trials, and shaded histograms are continuous replicate fishing periods (in water) while all other days involve the gillnet bagged in air (days dry). ACR, Australian cownose ray, Rhinoptera neglecta, WER, Whitespotted eagle ray, Aetobatus ocellatus; PDR, pygmy devilray, Mobula eregoodoo; WGF, whitespotted guitarfish, Rhynchobatus australiae; SS, spinner shark, Carcharhinus brevipinna; GHH, great hammerhead, Sphyrna mokarran; CBT, common blacktip shark, Carcharhinus limbatus; GNS, greynurse shark, Carcharias taurus; GT, green turtle, Chelonia mydas; LHT, loggerhead turtle, Caretta caretta. 


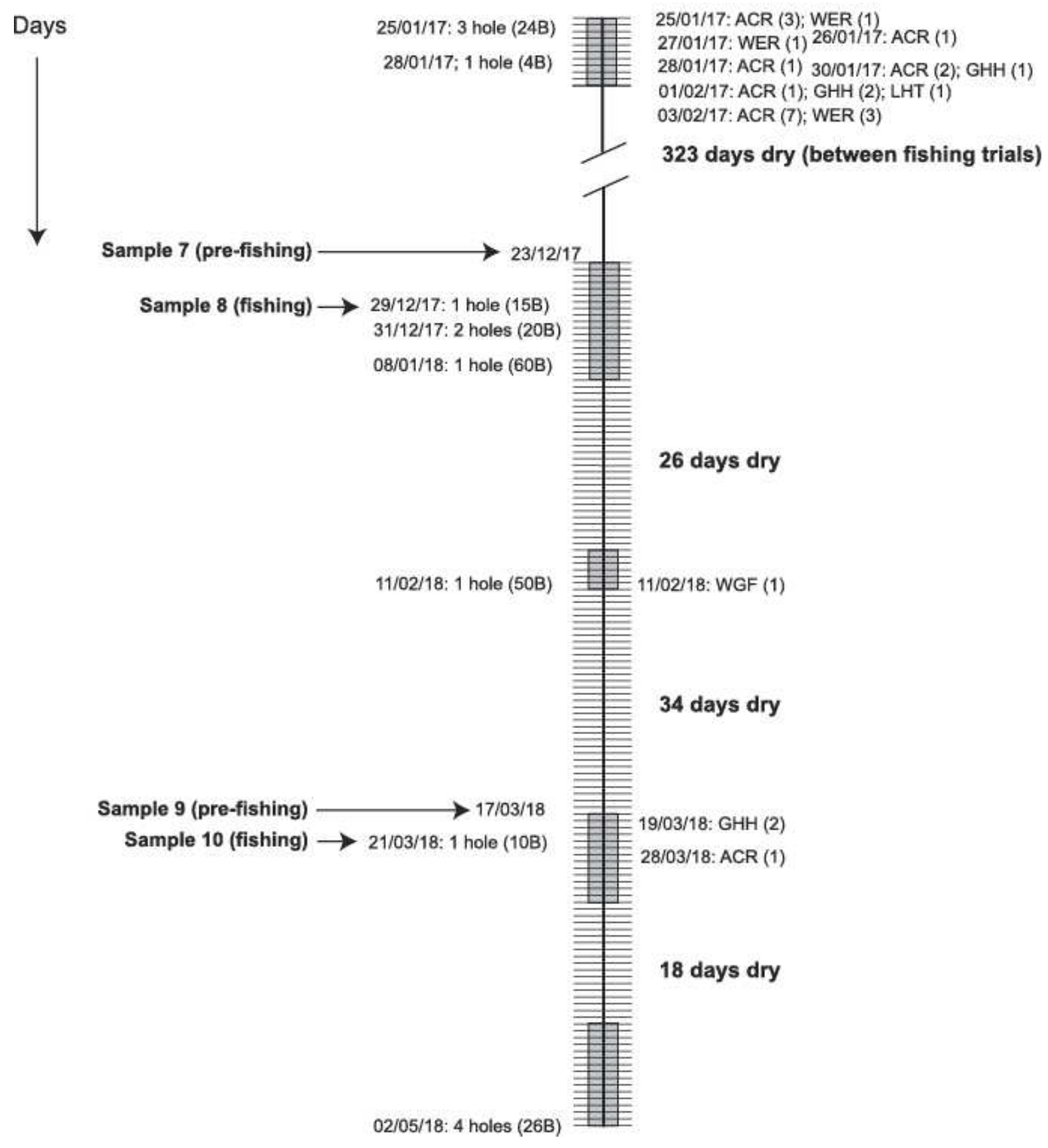

Fig. 3. Chronology of fishing (damage as holes and broken bars; $B$ and catches; $n=$ number) and sampling (eDNA collected) for gillnet no. 2 fished off Evans Head $\left(29.11^{\circ} \mathrm{S}, 153.44^{\circ} \mathrm{E}\right)$, Australia, with horizontal bars representing days in each of two fishing trials, and shaded histograms are continuous replicate fishing periods (in water) while all other days involve the gillnet bagged in air (days dry). ACR, Australian cownose ray, Rhinoptera neglecta, WER, Whitespotted eagle ray, Aetobatus ocellatus; GHH, great hammerhead, Sphyrna mokarran; LHT, loggerhead turtle, Caretta caretta. 
380 Table 1. Summary of filtered metabarcoding reads from consecutive (paired) samples for two primer sets targeting 12S mitochondrial DNA (Elasmo02 and MiFish). Only reads $>1 \%$ of total filtered reads per sample are shown. ${ }^{\wedge}$ possible contamination (see Results).

\begin{tabular}{|c|c|c|c|c|c|c|}
\hline Sample type, number, and date & Elasmo02 & Reads (\%) & Prior catch? & MiFish & Reads (\%) & Prior catch? \\
\hline Pre-fishing sample 1 & Sphyrna spp. & $114789(45.74)$ & Yes & Carcharhinus spp. & $1657(1.35)$ & Yes \\
\hline \multirow[t]{4}{*}{$23 / 11 / 17$} & Rhinoptera spp. & $46840(18.66)$ & Yes & Mobula spp. & $1537(1.25)$ & Yes \\
\hline & Carcharhinus spp. & $35114(13.99)$ & Yes & & & \\
\hline & Mobula spp.^ & $23476(9.35)$ & Yes & & & \\
\hline & Dasyatoidea spp. & $19216(7.66)$ & No & & & \\
\hline Positive control sample 2 & Carcharhinus spp. & $20861(16.17)$ & Yes & Mobula spp. & $4177(4.50)$ & Yes \\
\hline \multirow[t]{3}{*}{$29 / 11 / 17$} & Rhinoptera spp. & $12283(9.52)$ & Yes & Carcharhinus spp. & $3254(3.50)$ & Yes \\
\hline & Sphyrna spp. & $3300(2.56)$ & Yes & & & \\
\hline & Mobula spp. ${ }^{\wedge}$ & $4025(3.12)$ & Yes & & & \\
\hline Pre-fishing sample 3 & Aetobatus spp.^ & $47762(15.89)$ & Yes & & & \\
\hline \multirow{3}{*}{$19 / 01 / 18$} & Rhinoptera spp. & $37374(12.28)$ & Yes & & & \\
\hline & Pristiformes/Rhiniformes group & $26088(8.57)$ & Yes & & & \\
\hline & Greynurse shark, Carcharias taurus & $8719(2.87)$ & Yes & & & \\
\hline Fishing sample 4 & Sphyrna spp. & $88450(41.81)$ & Yes & Carcharhinus spp. & $1934(1.19)$ & Yes \\
\hline \multirow[t]{3}{*}{$23 / 01 / 18$} & Rhinoptera spp. & $45945(21.72)$ & Yes & Bull shark, Carcharhinus leucas & $1807(1.12)$ & No \\
\hline & Carcharhinus spp. & $42923(20.29)$ & Yes & & & \\
\hline & Carcharhinus spp. & $18297(8.65)$ & Yes & & & \\
\hline Fishing sample 5 & ${\text { Aetobatus spp } \wedge^{\wedge}}^{\prime}$ & $90917(32.35)$ & Yes & & & \\
\hline \multirow[t]{2}{*}{$23 / 01 / 18$} & Rhinoptera spp. & $42343(15.07)$ & Yes & & & \\
\hline & Sphyrna spp. & $5107(1.82)$ & Yes & & & \\
\hline Fishing sample 6 & Aetobatus spp.^ & $74912(85.48)$ & Yes & Aetobatus spp. & $10234(7.65)$ & Yes \\
\hline \multirow[t]{2}{*}{$02 / 02 / 18$} & Rhinoptera spp. & $5259(6.00)$ & Yes & & & \\
\hline & Sphyrna spp. & $6918(7.89)$ & Yes & & & \\
\hline Pre-fishino sample 7 & Mobula snn^^ & $77708(4240)$ & Yes & Rhinontera $\mathrm{snn}$ & $3963(311)$ & Yes \\
\hline \multirow[t]{3}{*}{$23 / 12 / 17$} & Aetobatus spp.^ & $71254(38.87)$ & Yes & & & \\
\hline & Sphvrna spp. & $17463(9.63)$ & Yes & & & \\
\hline & Rhinoptera spp. & $11401(6.22)$ & Yes & & & \\
\hline & & & & & & \\
\hline Fishing sample 8 & Aetobatus spp.^ & $77997(51.76)$ & Yes & Aetobatus spp. & $12932(14.20)$ & \\
\hline \multirow[t]{2}{*}{$29 / 12 / 17$} & Mobula spp..$^{\wedge}$ & $72686(48.23)$ & Yes & & & \\
\hline & & & & & & \\
\hline Pre-fishing sample 9 & Aetobatus spp.^ & $58494(26.46)$ & Yes & & & \\
\hline \multirow[t]{3}{*}{$17 / 03 / 18$} & Mobula spp. & $44840(20.28)$ & Yes & & & \\
\hline & Sphyrna spp. & 33011 (14.93) & Yes & & & \\
\hline & Pristiformes/Rhiniformes & $7100(3.21)$ & Yes & & & \\
\hline
\end{tabular}




\begin{tabular}{|c|c|c|c|c|c|c|}
\hline & & & & & & \\
\hline Fishing sample 10 & Aetobatus spp.^^ & $28449(14.45)$ & Yes & Delphinidae & $3571(2.91)$ & No \\
\hline \multirow[t]{4}{*}{$21 / 3 / 18$} & Mobula spp.^ & $20911(10.62)$ & Yes & & & \\
\hline & Sphyrna spp. & $20130(10.23)$ & Yes & & & \\
\hline & White shark, Carcharodon carcharias & $7312(3.71)$ & No & & & \\
\hline & Carcharhinus spp. & $3003(1.53)$ & No & & & \\
\hline
\end{tabular}


Figures

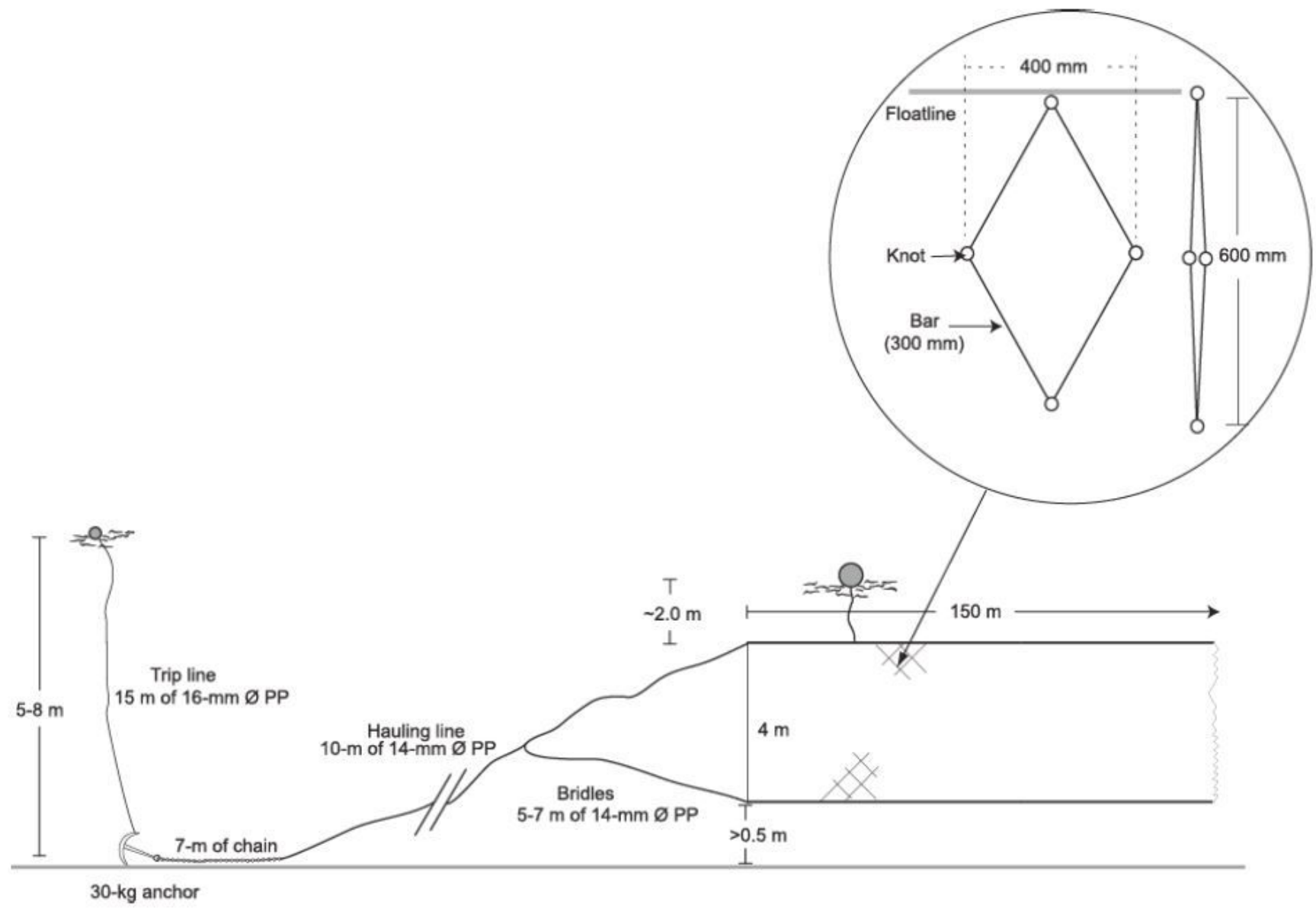

\section{Figure 1}

Schematic diagram of the bather-protection gillnets fished off Evans Head (29.110 S, 153.440 E), Australia. 


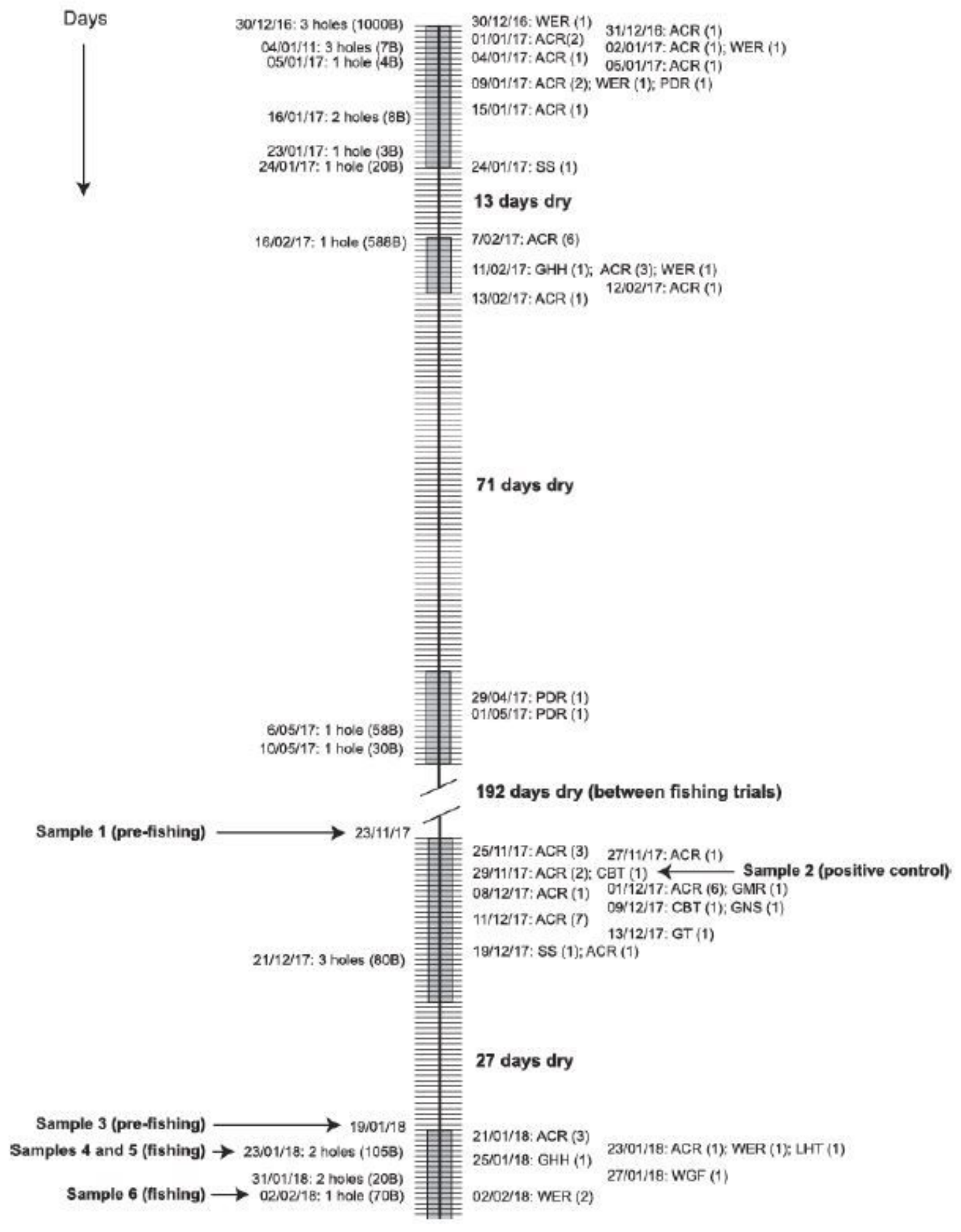

\section{Figure 2}

Chronology of fishing (damage as holes and broken bars; $\mathrm{B}$ and catches; $\mathrm{n}=$ number) and sampling (eDNA collected) for gillnet no. 1 fished off Evans Head (29.11o S, 153.44o E), Australia, with horizontal bars representing days in each of two fishing trials, and shaded histograms are continuous replicate fishing periods (in water) while all other days involve the gillnet bagged in air (days dry). ACR, Australian cownose ray, Rhinoptera neglecta, WER, Whitespotted eagle ray, Aetobatus ocellatus; PDR, pygmy 
devilray, Mobula eregoodoo; WGF, whitespotted guitarfish, Rhynchobatus australiae; SS, spinner shark, Carcharhinus brevipinna; GHH, great hammerhead, Sphyrna mokarran; CBT, common blacktip shark, Carcharhinus limbatus; GNS, greynurse shark, Carcharias taurus; GT, green turtle, Chelonia mydas; LHT, loggerhead turtle, Caretta caretta.
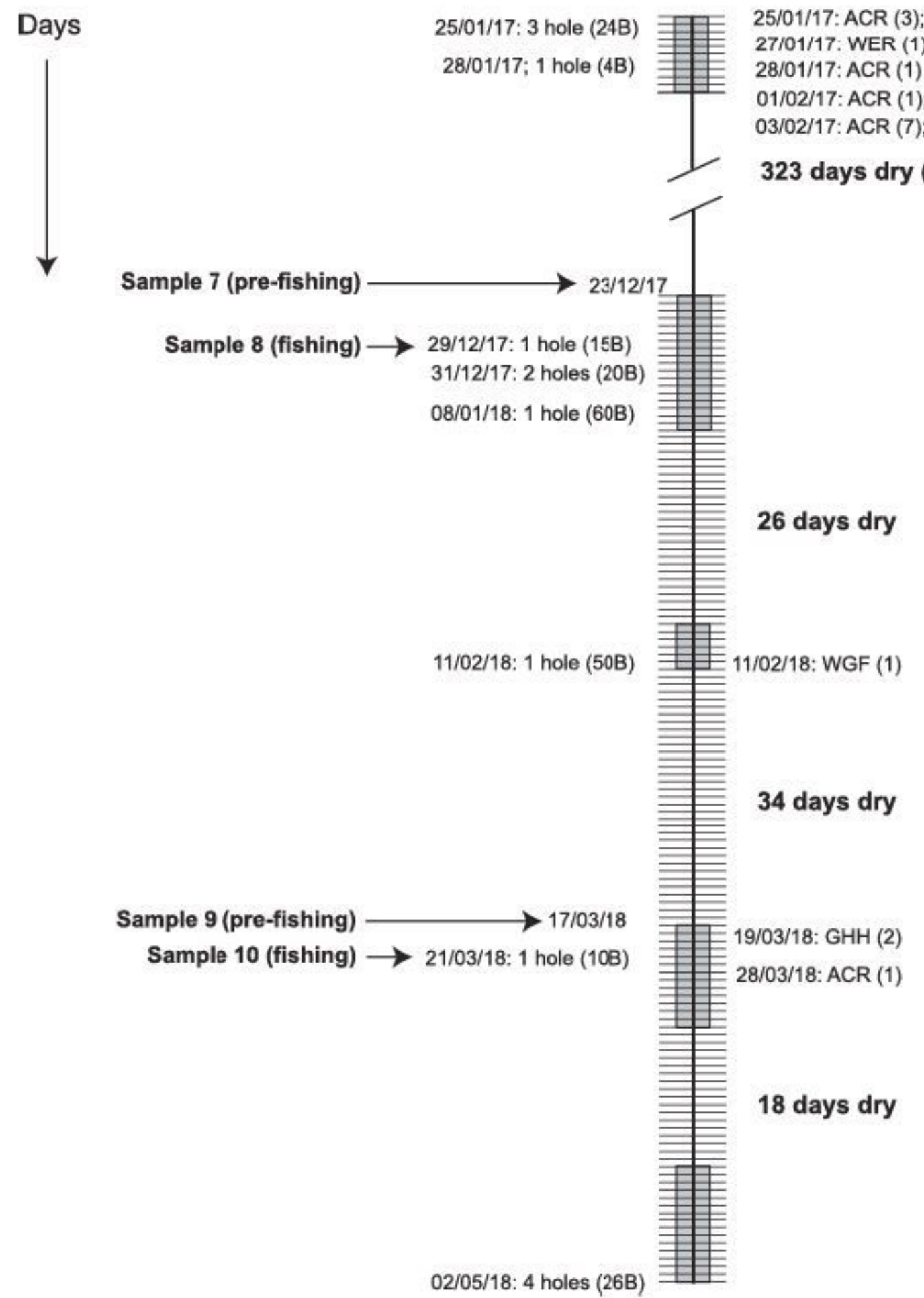

Figure 3 
Chronology of fishing (damage as holes and broken bars; $\mathrm{B}$ and catches; $\mathrm{n}=$ number) and sampling (eDNA collected) for gillnet no. 2 fished off Evans Head (29.11o S, 153.44o E), Australia, with horizontal bars representing days in each of two fishing trials, and shaded histograms are continuous replicate fishing periods (in water) while all other days involve the gillnet bagged in air (days dry). ACR, Australian cownose ray, Rhinoptera neglecta, WER, Whitespotted eagle ray, Aetobatus ocellatus; GHH, great hammerhead, Sphyrna mokarran; LHT, loggerhead turtle, Caretta caretta.

\section{Supplementary Files}

This is a list of supplementary files associated with this preprint. Click to download.

- SupplementaryTable1.xlsx 